Pesq. Vet. Bras. 28(4):195-200,abril 2008

\title{
Análises histológica e morfométrica do uso de membrana biossintética de celulose em trocleoplastia experimental de cães ${ }^{1}$
}

\author{
Luciana S. lamaguti2*, Cláudia V.S. Brandão², Claudia H. Pellizzon³, José J.T. \\ Ranzani² e Bruno W. Minto ${ }^{2}$
}

\begin{abstract}
L.S., Brandão C.V.S., Pellizzon C.H., Ranzani J.J.T. \& Minto B.W. 2008. [Histological and morphometric analysis for the use of a biosynthetic cellulose membrane in experimental trochleopasty.] Análises histológica e morfométrica do uso de membrana biossintética de celulose em trocleoplastia experimental de cães. Pesquisa Veterinária Brasileira 28(4):195-200. Departamento de Cirurgia e Anestesiologia, Faculdade de Medicina Veterinária e Zootecnia, Universidade Estadual Paulista, Campus de Botucatu, Distrito de Rubião Jr s/n, Botucatu, SP 18.618-000, Brazil. E-mail: iamaguti_lu@ hotmail.com

The aim of this study was to evaluate the use of a locally made biosynthetic cellulose membrane after experimental trochleoplasty, in order to verify whether its use could support migration of chondrogenic cells. Twelve male and female adult healthy dogs and without claudication were used. All dogs were submitted to trochleoplasty in both pelvic limbs after sedation and epidural anesthesia. In the left hind limb, the biosynthetic cellulose membrane was fixed with simple suture using Polyglactin 910 6-0 after performing trochleoplasty (treated group); whereas in the right limb (control group) only trochleoplasty was performed. The dogs were subdivided into 4 subgroups for postoperative evaluation at 15, 30, 60 and 90 days post-surgery. Biopsy was performed after exploratory arthrotomy for histopathologic and morfometric evaluation. At 30 and 60 days post-surgery, more condrocyte-like cells of immature aspect were observed in lesions treated with the cellulose membrane. At 90 days post-surgery the reparative tissue was characterized as mature fibrocartilage-like tissue without difference between the groups. In the control group there was a progressive increase of the number of cells until the end of the evaluation period. Otherwise, when compared to the initial period (15 days), there was an increase in the number of cells until 60 days, followed by a return the initial values at 90 days in the treated group. In comparison to controls, the number of cells was greater in the treated group from 15 to 60 days. Initially, the neoformed repair tissue was thicker in the treated group. From the results of this study, it was concluded that the cellulose membrane shortened the initial tissue repair process in the trochleoplasty area, showing good integration of the neoformed tissue with the adjacent cartilage.
\end{abstract}

INDEX TERMS: Sulcoplasty, physical barrier, guided tissue regeneration, dog.

\footnotetext{
${ }^{1}$ Recebido em 24 de agosto de 2007.

Aceito para publicação em 15 de janeiro de 2008.

Parte da Dissertação de Mestrado do primeiro autor.

2 Departamento de Cirurgia e Anestesiologia, Faculdade de Medicina Veterinária e Zootecnia (FMVZ), Universidade Estadual Paulista (Unesp), Campus de Botucatu, Distrito de Rubião Jr s/n, Botucatu, SP 18618-000, Brasil. *Autor para correspondência: iamaguti_lu@ @otmail.com 3 Instituto de Biociências de Botucatu, Unesp-Botucatu, Distrito Rubião Jr s/n, Botucatu, SP.
}

RESUMO.- O objetivo deste trabalho foi avaliar a aplicação de membrana biossintética de celulose, de fabricação nacional, após a realização da trocleoplastia experimental, com intuito de verificar se o uso desta poderia favorecer a migração de células com potencial condrogênico. Foram utilizados 12 cães adultos, de ambos os sexos, sadios e sem alterações no aparelho locomotor. Os animais foram submetidos ao procedimento de trocleoplastia em ambos os membros pélvicos, após tranquiliza- 
ção e anestesia epidural. $\mathrm{Na}$ trocleoplastia do membro esquerdo foi aplicada membrana biossintética à base de celulose (grupo tratado, GT), fixada à cartilagem por meio de pontos simples separados com Poliglactina 910 6-0; no membro direito, foi realizada apenas a trocleoplastia, constituindo o grupo controle (GC). Os animais foram subdivididos em quatro subgrupos de acordo com o período final de avaliação aos 15, 30, 60 e 90 dias do pós-operatório. Após artrotomia exploratória nos momentos pré-estabelecidos, foi realizada biópsia da região da trocleoplastia para avaliação histológica e morfométrica do tecido de reparação. Aos 30 e 60 dias do pós-operatório, notou-se a presença de maior número de células semelhantes a condrócitos nas lesões tratadas com celulose em relação ao membro contra-lateral, apesar do aspecto imaturo. Aos 90 dias, o tecido de reparação era do tipo fibrocartilaginoso maduro, não havendo diferenças entre os dois grupos. No GC houve aumento progressivo do número de células até o período final de avaliação. Por outro lado no grupo tratado verificou-se que, em relação ao período inicial (15 dias), houve aumento do número de células até os 60 dias, com subseqüente retorno aos valores iniciais aos 90 dias. Dos 15 aos 60 dias o número de células foi maior no GT em relação ao GC. Inicialmente, o tecido de reparação neoformado foi mais espesso no grupo tratado. Dessa forma, conclui-se que a membrana de celulose acelerou o processo de reparação tecidual inicial da região da trocleoplastia, apresentando boa integração do tecido neoformado com a cartilagem adjacente.

TERMOS DE INDEXAÇÃO: Sulcoplastia, barreira física, regeneração tecidual guiada, cão.

\section{INTRODUÇÃO}

A trocleoplastia consiste em uma das principais técnicas de correção cirúrgica para a luxação de patela em cães (Hulsen 1981, Farias 1995, lamaguti et al. 1995, Gareth \& Sorrel 2006). Contudo, a progressão da osteoartrite sugere que a biomecânica da articulação mantenha-se alterada mesmo após a cirurgia, devido à ausência de total restabelecimento da anatomofisiologia articular (Roy et al. 1992, Gareth \& Sorrel 2006). Um elemento estratégico para o sucesso na reparação de defeitos na superfície articular constitui a introdução de enxertos, biomateriais ou outros fatores de alto potencial condrogênico nas lacunas cartilaginosas (Mow 1991, Messner \& Gillquist 1993). Membranas biossintéticas apresentam boa aceitação pelo organismo, protegendo e auxiliando a reparação de áreas lesadas por permeabilidade seletiva, além de impedir a contaminação por microorganismos (Carvalho et al. 2003, Aslan et al. 2004). Vários tipos de membranas importadas são descritas, como a de politetrafluoroetileno (PTFE) (Messner \& Gillquist 1993), silicone (Biobrane $\AA$ ) (Warrer \& Karring 1992), ácido poliglicólico e ácido polilático (Ma \& Langer 1999), colágeno (Schuman et al. 1995). Devido às dificuldades de obtenção, importação e conseqüentemente alto custo no Brasil para o uso de biopolímeros ou membranas biológicas, tornou-se evidente a necessidade de se buscar um material nacional que possa ser usado para esse fim (Novaes Jr et al. 1993).

O emprego de barreiras físicas com a finalidade de regenerar defeitos ósseos tem sido descrito na literatura com o nome de Regeneração Tecidual Guiada (RTG) (Novaes Jr et al. 1993, Novaes Jr. et al. 2002, Macedo et al. 2004, Aslan et al. 2004). Baseando-se nesta propriedade, surgiu a idéia de verificar se no tecido cartilaginoso articular, a colocação da membrana de celulose também favoreceria a migração de células com potencial condrogênico, assim como ocorre no tecido ósseo.

Frente aos fatos acima citados, com o enfoque no processo de reparação da cartilagem, objetivou-se analisar histo e morfometricamente a utilização de membrana biológica biossintética nacional, à base de celulose, em trocleoplastias experimentais em cães, comparando os resultados obtidos entre os tratamentos com e sem a membrana.

\section{MATERIAL E MÉTODOS}

Foram utilizados 12 cães hígidos, sem raça definida, provenientes do Biotério Central da Universidade Estadual Paulista, Campus de Botucatu, sendo cinco machos e sete fêmeas, com faixa etária entre um e três anos, e peso médio de 10,5 $\pm 1,9 \mathrm{~kg}$.

Constituíram-se dois grupos experimentais designados: Grupo Controle (GC), membro direito submetido à realização da trocleoplastia, e o Grupo Tratado (GT), membro esquerdo no qual a membrana biossintética à base de celulose (MBC) de 5 micrometros de espessura foi fixada após trocleoplastia. Sob circunstâncias assépticas, após tranqüilização e anestesia epidural, realizou-se incisão da pele parapatelar lateral de 5 a 7cm, seguida da incisão do retináculo e cápsula articular, até a exposição da articulação do joelho. Com o membro em extensão, a patela foi deslocada medialmente, expondo-se a tróclea femoral. O joelho foi, então, flexionado para realização da trocleoplastia, por meio do aprofundamento do sulco troclear com auxílio de goiva e lima, retirando-se toda a superfície de contato com a face articular da patela, até o sangramento do osso subcondral. No membro esquerdo dos cães, após o aprofundamento do sulco, a MBC foi fixada com pontos simples separados na borda cartilaginosa normal, com a utilização de fio de sutura absorvível sintético 6-0. A patela foi reposicionada anatomicamente e foram realizadas as sínteses da cápsula articular e do retináculo em pontos tipo "Sultan", do tecido subcutâneo em padrão contínuo e da pele com pontos simples separados utilizando-se fio náilon monofilamento 3-0.

Em cada grupo experimental, os animais foram distribuídos, por sorteio aleatório, em quatro subgrupos de três cães, de acordo com os diferentes momentos (M) de observação, ou seja, 15 (M15), 30 (M30), 60 (M60) e 90 (M90) dias do pósoperatório. Os animais foram avaliados clinicamente quanto à claudicação. Nos diferentes momentos de observação, de acordo com o subgrupo do animal, foi realizada artrotomia exploratória para a obtenção de biópsia $(2 \times 0,5 \mathrm{~cm})$ do sulco troclear visando o exame histomorfométrico.

As biópsias ósseas, obtidas da região da trocleoplastia do 
GC e GT e da cápsula articular próximo à linha de incisão, foram avaliadas por meio de microscopia óptica e a seguir, acondicionadas em solução tamponada de Formaldeído a 10\%.

Os fragmentos da região da trocleoplastia foram descalcificados em ácido nítrico 5\%; sendo posteriormente processados, juntamente com o fragmento da cápsula articular, de acordo com rotina histológica padrão e corados pelos métodos de Hematoxilina-Eosina (HE) e Tricrômico de Masson. Na análise histológica, a resposta biológica foi determinada em função do processo de reparação da cartilagem, alterações vasculares e presença de infiltrado inflamatório.

A análise morfométrica foi processada, utilizando-se o software Leica QWin® Standard Versão 3.1.0. de captura de imagens acoplado ao microscópio DM Leica $₫$, sem o conhecimento prévio dos grupos experimentais em método de duplo cego. A região central da trocleoplastia foi utilizada como padrão para análise morfométrica. Nesta, foram avaliados o número de células, utilizando o método de contagem total de células num campo de $156531,41 \mu \mathrm{m}^{2}$ por método manual, e a espessura do tecido de reparação no defeito cirúrgico, utilizando-se o método semi-automatico dentro do programa Leica QWin® Standard Versão 3.1.0, no qual as extremidades das medidas foram definidas manualmente.

O procedimento quantitativo das variáveis estudadas foi realizado pela técnica da análise de variância para o modelo com dois fatores, complementada com os respectivos testes de comparações múltiplas. Para a contagem do número de células, considerou-se a técnica não paramétrica, enquanto que para a espessura, a técnica paramétrica. Todas as comparações foram realizadas ao nível de $5 \%$ de significância (Zar 1999). Os animais foram doados após o experimento.

\section{RESULTADOS E DISCUSSÃO}

\section{Avaliação clínica e de ambulatória}

O procedimento cirúrgico e o pós-operatório dos animais transcorreram de maneira bastante tranqüila. A maioria dos cães não apresentou claudicação em quaisquer dos períodos observados, apenas um animal apresentou claudicação discreta do membro pélvico esquerdo (GT) nas primeiras 24 horas, permanecendo até o segundo dia após a cirurgia. Dessa forma, a cirurgia bilateral realizada em um único ato operatório não proporcionou transtornos consideráveis, visto que os animais retornaram à função normal do membro, precocemente, discordando dos relatos de Farias (1995).

\section{Avaliação histológica}

A avaliação morfológica do tecido neoformado na região da trocleoplastia está apresentada no Quadro 1.

Deve-se ressaltar que as técnicas de coloração utilizadas foram adequadas para a observação da resposta biológica determinada pelo processo de reparação da cartilagem, alterações vasculares e presença de condrócitos, fibroblastos, osteoclastos e infiltrado inflamatório. As colorações permitem a visualização adequada da celularização e da matriz cartilaginosa, sendo recomendadas por Behrmer et al. (1976). Tricrômico de Masson é utilizado para o estudo de fibras colágena (parte de reposição da matriz) enquanto o HE evidencia condroblasto, condrócitos com grande fidelidade e matriz cartilaginosa basófilica.

$\mathrm{Na}$ avaliação histológica do sulco troclear, notou-se que, aos 15 dias, não houve diferença entre GC e GT; verificou-se, portanto, que a cartilagem hialina da superfície articular foi substituída por tecido conjuntivo de estrutura delicada, rico em fibroblastos e numerosos vasos sanguíneos de diferentes diâmetros, semelhante ao descrito por Farias (1995). Deve-se ressaltar que além de se tratar da fase inicial do processo de reparação celular, o osso subcondral foi acessado no procedimento de trocleoplastia, sendo com isso fonte primária para o desenvolvimento de tal resposta. Dessa forma, foi verificado que a reparação foi obtida com tecido do tipo fibrocartilaginoso que possui características biomecânicas inferiores à cartilagem articular original (Malmonge et al. 2000, Simon \& Jackson 2006).

Contudo, foi notada diferença entre GC e GT aos 30 e 60 dias do pós-operatório, sendo que, nestes dois perío-

Quadro 1. Características histológicas da região da trocleoplastia em cães com e sem o uso da MBC, nos diferentes momentos de avaliação

\begin{tabular}{|c|c|c|}
\hline \multirow{2}{*}{$\begin{array}{l}\text { Momentos de } \\
\text { avaliação }\end{array}$} & \multicolumn{2}{|c|}{ Grupos } \\
\hline & Controle & Tratado \\
\hline M15 & $\begin{array}{l}\text { Camada delgada de tecido conjuntivo do tipo fibrocar- } \\
\text { tilaginoso; lesão central evidente e recoberta por ma- } \\
\text { terial acidófilo (matriz óssea) envolto por intensa fibro- } \\
\text { se; presença de alguns macrófagos, linfócitos e osteo- } \\
\text { clastos }\end{array}$ & $\begin{array}{l}\text { Camada delgada de tecido conjuntivo do tipo fibrocar- } \\
\text { tilaginoso; lesão central evidente e recoberta por ma- } \\
\text { terial acidófilo (matriz óssea) envolto por intensa fibro- } \\
\text { se; presença de alguns macrófagos, linfócitos e osteo- } \\
\text { clastos }\end{array}$ \\
\hline M30 & $\begin{array}{l}\text { Intensa celularidade, constituída por fibroblastos ativos, } \\
\text { vascularização evidente e presença de macrófagos e } \\
\text { osteoclastos, fibrose menos intensa }\end{array}$ & $\begin{array}{l}\text { Intensa celularidade, na região superficial verificou-se } \\
\text { células de aspecto fusiforme e, na profunda, células com } \\
\text { formato estrelado, semelhantes a condrócitos imatu- } \\
\text { turos. Menor quantidade de macrófagos e fibrose apa- } \\
\text { rente; vascularização menos intensa; tecido conjuntivo } \\
\text { mais organizado }\end{array}$ \\
\hline M60 & $\begin{array}{l}\text { Células justapostas na região superficial, além de mui- } \\
\text { tos fibroblastos em região mais profunda; fibrose }\end{array}$ & $\begin{array}{l}\text { Maior número de células com formato de condrócitos, } \\
\text { vascularização e células justapostas pouco evidentes }\end{array}$ \\
\hline M90 & $\begin{array}{l}\text { Células justapostas, presença de fibroblastos e condró- } \\
\text { citos, sem fibrose; tecido de reparação do tipo fibrocar- } \\
\text { tilaginoso maduro, vascularização menos evidente }\end{array}$ & $\begin{array}{l}\text { Células justapostas, presença de fibroblastos e con- } \\
\text { drócitos, sem fibrose; tecido de reparação do tipo fibro- } \\
\text { cartilaginoso maduro, vascularização menos evidente }\end{array}$ \\
\hline
\end{tabular}


dos, verificou-se a presença de maior número de células semelhantes a condrócitos nas lesões recobertas com a membrana de celulose, sugerindo o desenvolvimento de tecido com maior prevalência de células cartilaginosas imaturas (Fig.1). Na região de trocleoplastia do GC, foi observada maior quantidade de fibroblastos ativos, além da fibrose sobre a lesão (Fig.2). Dessa forma, o processo de reparação iniciou-se com 30 dias no GT. Estudos relataram início do processo aproximadamente aos 45 dias com utilização de enxertos cartilaginosos, biomateriais ou outros fatores com alto potencial condrogênico em 24 cabras distribuidas em 8 grupos de 3 animais (Jackson et al. 2001, Simon \& Jackson 2006). Isto sugere que a membrana de celulose pode ter acelerado o processo de reparação da cartilagem articular e melhorado a evolução histológica, direcionando e organizando a resposta cicatricial. O uso de uma membrana separando compartimen-

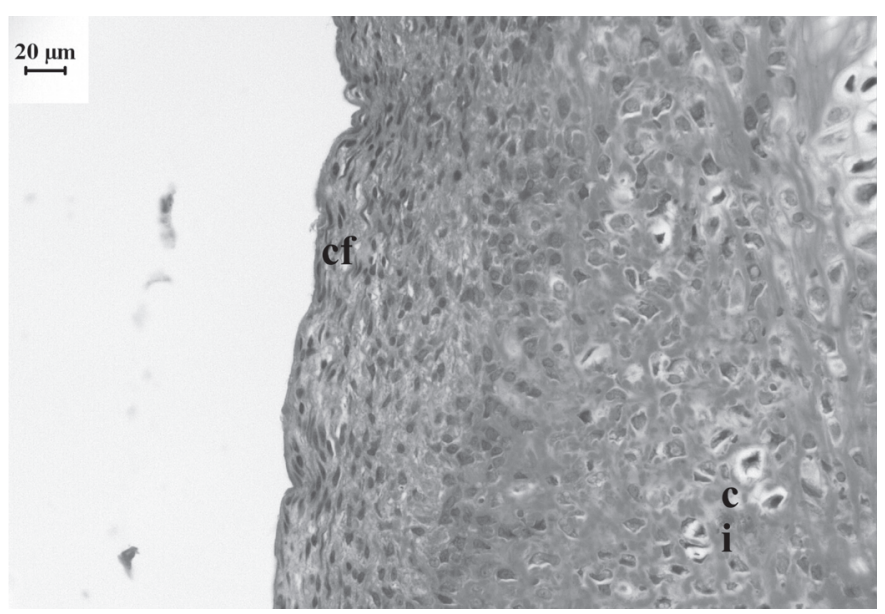

Fig.1. Região central da trocleoplastia do GT aos 30 dias. Intensa celularidade, com células de aspecto fusiforme (cf) na região superficial e com formato estrelado na profunda, semelhantes à condrócitos imaturos (ci). HE, obj.40x

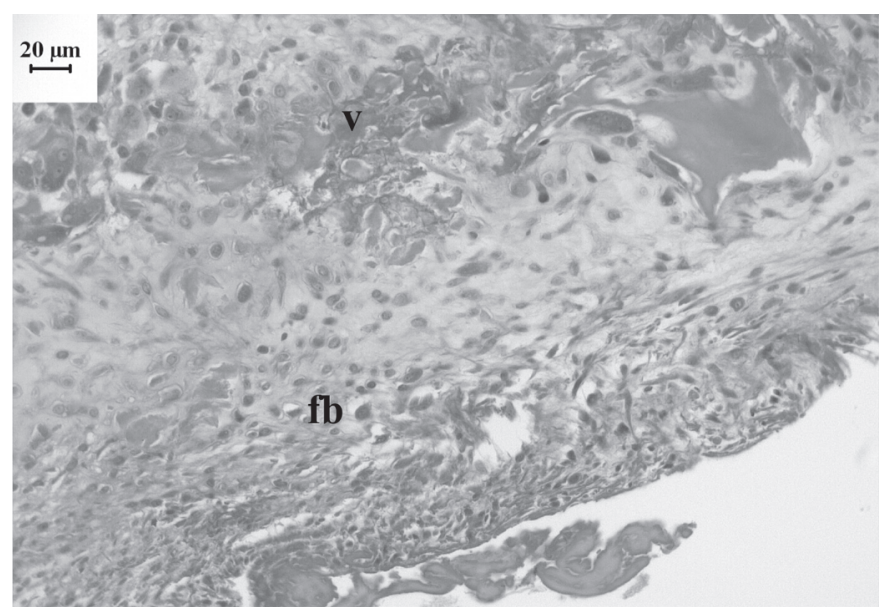

Fig.2. Região central da trocleoplastia do GC aos 30 dias. Intensa celularidade, constituída por fibroblastos ativos (fb), vascularização evidente (v) e fibrose menos intensa. HE, obj.40x tos teciduais para prevenção de crescimento de tecidos indesejáveis pode ser considerado uma variação do princípio da RGT, de acordo com Nyman (1991).

A integração do tecido neoformado com o tecido adjacente foi observada em todos os grupos nos diferentes momentos, diferente do encontrado por Malmonge et al. (2000) em estudo avaliando a reparação de defeitos intercondilares de fêmures de ratos. O estímulo promovido pelo deslizamento patelar no sulco troclear pode ter contribuído para esta melhor integração, à semelhança do observado por Farias (1995), após aprofundamento do sulco troclear em cães.

$\mathrm{Na}$ avaliação da cápsula articular não foram observadas alterações, nem reação inflamatória em nenhum animal e momento avaliado, apenas infiltrado mononuclear mais intenso ao redor do fio cirúrgico com proliferação de tecido conjuntivo denso. Isto sugere que a membrana de celulose foi biocompatível, não proporcionando formação de debris e reações de corpo estranho nem induzindo sinovites como descrito, em coelhos, por Messner \& Gillquist (1993). Observou-se, portanto, que a membrana apresentou característica biodegradável e não interferiu negativamente no ambiente intra-articular, similar ao descrito por Salata et al. (2001).

A membrana apresentou boa aceitação pelo organismo, auxiliando nas fases iniciais do processo de reparação da região da trocleoplastia, semelhante ao descrito por Carvalho et al. (2003) e Aslan et al. (2004). A celulose sofreu degradação no organismo animal, não sendo identificada, macro ou histologicamente, em nenhum grupo. O processo bioquímico de degradação da celulose deverá ser esclarecido segundo relataram Mello et al. (2001).

\section{Análise morfométrica}

O número de células, de acordo com o grupo e os momentos avaliados, está apresentado no Quadro 2 e Figura 3, enquanto a espessura do tecido de reparação está representada no Quadro 3 e Figura 4.

Quanto à análise morfométrica, não foram encontrados dados na literatura consultada a respeito dessa avaliação utilizando membranas biológicas. No GC houve aumento progressivo do número total de células até o período final de avaliação; quando se analisou o GT, verificou-se que, em relação ao período inicial, essa diferen-

\section{Quadro 2. Mediana e amplitude interquartílica do número de células segundo o grupo experimental e momentos de avaliação}

\begin{tabular}{lllrl}
\hline \multirow{2}{*}{ Grupos } & \multicolumn{4}{c}{ Momentos de avaliação } \\
\cline { 2 - 5 } & 15 dias & 30 dias & 60 dias & 90 dias \\
\hline
\end{tabular}

Controle 590,5 $\pm 105,5 a A^{*} \quad 923,0 \pm 112,5 a B \quad 920,0 \pm 360,5 a B ~ 1076,5 \pm 311,3 b B$ Tratado $893,0 \pm 183,8 b A B \quad 1073,5 \pm 201,3 b B C 1483,0 \pm 455,4 b C \quad 690,0 \pm 219,5 a A$

*Letras minúsculas indicam comparação entre grupos nos diferentes momentos de avaliação. Letras maiúsculas indicam comparação do grupo nos diferentes momentos de avaliação. Médias de grupos seguidas de mesma letra não diferem estatisticamente. 


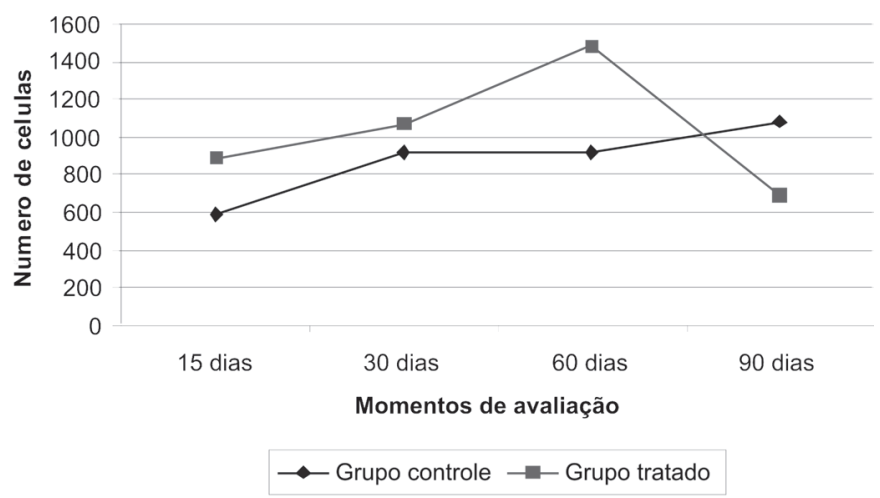

Fig.3. Valores médios do número de células da região da trocleoplastia segundo o grupo experimental e momentos avaliados. Médias de grupos seguidas de mesma letra não diferem estatisticamente $(P>0,05)$. Letras minúsculas indicam comparação entre grupos nos diferentes momentos de avaliação. Letras maiúsculas indicam comparação do grupo nos diferentes momentos de avaliação.

\section{Quadro 3. Média e desvio padrão da espessura do tecido de reparação na região da trocleoplastia, em micrometros, segundo o grupo experimental e momentos de avaliação}

\begin{tabular}{lllll}
\hline Grupos & \multicolumn{4}{c}{ Momentos de avaliação } \\
\cline { 2 - 4 } & 15 dias & 30 dias & 60 dias & 90 dias \\
\hline
\end{tabular}

Controle $155,5 \pm 26,0 \mathrm{aA} * \quad 146,8 \pm 33,4 \mathrm{aA} \quad 166,7 \pm 14,1 \mathrm{aA} \quad 174,3 \pm 44,4 \mathrm{bA}$ Tratado $154,9 \pm 23,3 a A B \quad 263,9 \pm 34,5 b C 206,0 \pm 35,4 a B C 121,5 \pm 12,8 a A$

*Letras minúsculas indicam comparação entre grupos nos diferentes momentos de avaliação. Letras maiúsculas indicam comparação do grupo nos diferentes momentos de avaliação. Médias de grupos seguidas de mesma letra não diferem estatisticamente.

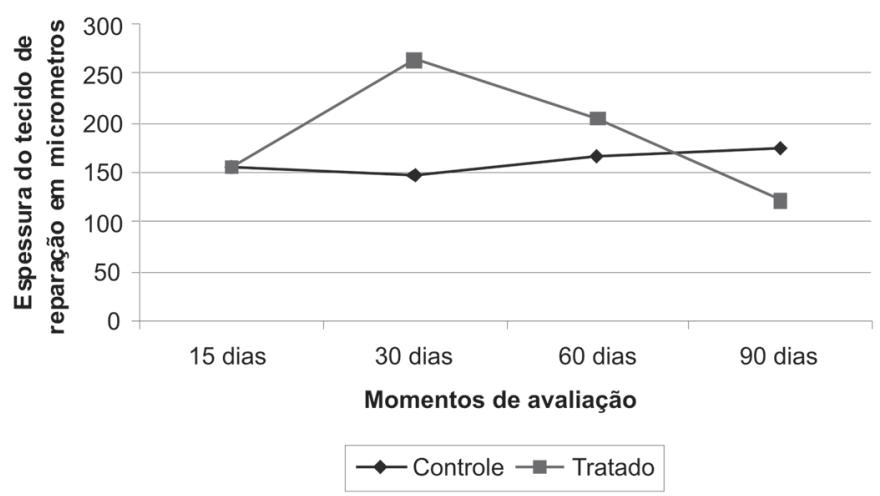

Fig.4. Valores médios da espessura do tecido de reparação da região da trocleoplastia em micrometros segundo o grupo experimental e momentos avaliados. Médias de grupos seguidas de mesma letra não diferem estatisticamente $(P>0,05)$. Letras minúsculas indicam comparação entre grupos nos diferentes momentos de avaliação. Letras maiúsculas indicam comparação do grupo nos diferentes momentos de avaliação.

ça ocorreu até os 60 dias, sendo verificado retorno aos padrões iniciais aos 90 dias. Este fato foi corroborado pela espessura do tecido de reparação neoformado seguindo padrão semelhante, e pela observação, à microscopia, de tecido conjuntivo mais organizado conforme a evolução do processo. Além disso, o número total de células no GT foi superior ao encontrado no GC até os 60 dias do pós-operatório, sendo esse comportamento invertido aos 90 dias. A evolução do número de células sugere que a membrana de celulose pode ter favorecido a migração de células cartilaginosas com potencial para reparação na fase inicial de acordo com os princípios da Regeneração Tecidual Guiada, uma vez que se verificou maior celularidade nas fases mais precoces do experimento; no entanto, aos 90 dias, notou-se a formação de um tecido fibrocartilaginoso mais organizado e maduro, com menor presença de células em relação ao GC; isto foi decorrente da tendência de estabilização do processo de reparação.

A fase de reparação na trocleoplastia não foi limitada devido ao aporte sanguíneo e celular a partir do osso subcondral, já que os vasos sanguíneos deste tecido foram atingidos, seguindo o processo de reparação de uma lesão profunda. Dessa forma, as células promotoras tiveram acesso à lesão proporcionando a formação de tecido composto por fibrocartilagem (Simon \& Jackson 2006).

Membranas ou outros suportes podem ser usados como método auxiliar na implantação de células indiferenciadas, cartilaginosas ou outros fatores potencialmente condrogênicos (Messner \& Gillquist, 1993; Schuman et al. 1995, Ma \& Langer 1999, Malmonge et al. 2000).

O estudo de reparação de cartilagem, apesar de amplamente descrito na literatura e datado de longas décadas, ainda merece atenção e destaque. Vários outros estudos, na tentativa de adicionar fatores que influenciem positivamente tal resposta, devem ser estimulados, assim como o uso de membrana de celulose ou outros biomateriais.

\section{CONCLUSÃO}

A análise dos resultados obtidos, nas condições experimentais deste trabalho, permite concluir que a membrana de celulose acelerou o processo de reparação inicial da região da trocleoplastia, apresentando boa integração do tecido neoformado com a cartilagem adjacente. A membrana biossintética de celulose, como elemento isolado, não é efetiva para promover completa regeneração da cartilagem articular.

Agradecimentos.- À CAPES pela bolsa e à Fundunesp pelo auxílio pesquisa. Ao Prof. Younes Messadeq do Departamento de Química Geral e Inorgânica, Instituto de Química, Unesp-Araraquara, pela disponibilização da membrana biossintética. Ao Prof. Titular Carlos Roberto Padovani do Departamento de Bioestatística do Instituto de Biociências, Unesp-Botucatu, pela execução da análise estatística.

\section{REFERÊNCIAS}

Aslan M., Simsek G. \& Dayl E. 2004. Guided bone regeneration (GBR) on healing bone defects: a histological study in rabbits. J. Contemp. Dent. Pract. 2(5):114-123.

Behmer O.A., Tolosa E.M.C. \& Freitas Neto A.G. 1976. Manual de Técnicas para Histologia Normal e Patológica. EDART, Editora da USP, São Paulo. 
Carvalho R.S., Nelson D., Kelderman H. \& Wise R. 2003. Guided bone regeneration to repair an osseous defect. Am. J. Orthod. Dentofacial Orthop. 123:455-467.

Farias L.L. 1995. Aprofundamento experimental do sulco troclear no tratamento da luxação da patela no cão: avaliação clínica, histológica e radiográfica. Dissertação de Mestrado, área de Clínica Veterinária, Faculdade de Medicina Veterinária e Zootecnia, Universidade Estadual Paulista. 63p.

Gareth I.A. \& Sorrel J.L.H. 2006. Complications associated with corrective surgery for patellar luxation in 109 dogs. Vet. Surg. 35:559-566.

Hulsen D.A. 1981. Pathophysiology and management of medial patellar luxation in the dog. Vet. Med. Small Anim. Clin. 76:43-51.

lamaguti P., Prado L., Del Carlo R.J., Vulcano L.C., Mamprim M.J. \& Dal Pai V. 1995. Patelectomia e aprofundamento do sulco troclear no tratamento de luxação de patela: estudo experimental em coelhos. Vet. Zootec. 7:85-99.

Jackson D.W., Lalor P.A., Aberman H.M. \& Simon T.W. 2001. Spontaneous repair of full-thickness defects of articular cartilage in a goat model. J. Bone Joint Surg. 83A(1):53-64.

Ma P.X. \& Langer R. 1999. Morphology and mechanical function of long-term in vitro enginnered cartilage. J. Biomed. Mater. Res. 44:217221.

Macedo N.L., Matuda F.S., De Macedo L.G., Monteiro A.S.F., Valera M.C. \& Carvalho R. 2004. Evaluation of two membranes in guided bone tissue regeneration: histological study in rabbits. Braz. J. Oral Sci. 3(8):395-400.

Malmonge S.M., Zavaglia C.A.C. \& Belangero W.D. 2000. Biomechanical and histological evaluation of hydrogel implant in articular cartilage. Braz. J. Med. Biol. Res. 33:307-312.

Mello L. R., Feltrin Y., Selbach R., Macedo Jr G., Spautz C. \& Haas L.J. 2001. Uso da celulose liofilizada em lesões de nervos periféricos com perda de substância. Arq. Neuro-Psiquiatr. 59(2B).

Messner K. \& Gillquist J. 1993. Synthetic implants for the repair of osteochondral defects of the medial femoral condyle: a biomechanical and histological evaluation in the rabbit knee. Biomaterials 14(7):513521.

Mow V.C., Ratcliffe A., Rosenwasser M.P. \& Buckwanter J.A. 1991. Experimental studies on repair of large osteochondral defects at a high weight bearing area of the knee joint: $A$ tissue engineering study. Transactions ASME 113:198-206.

Novaes Jr A.B., Novaes A.B., Grisi M.F.M., Soares U.N. \& Gabarra F. 1993. Gengiflex, an alkali-cellulose membrane for GTR: Histologic observations. Braz. Dent. J. 4(2):65-71.

Novaes Jr A.B., Papalexiou V., Luczyszyn S.M., Muglia V., Souza S.L.S. \& Taba M. 2002. Immediate implant in extraction socket with acellular dermal matrix graft and bioactive glass: a case report. Implant Dentistry 11(4):343-348.

Nyman S. 1991. Bone regeneration using the principle of guided tissue regeneration. J. Clin. Periodontol. 18:494-498.

Roy R.G., Wallace L.J., Johnston G.R. \& Wickstrom S.L. 1992. A retrospective evaluation of stifle osteoarthritis in dog with bilateral medial patellar luxation and unilateral surgical repair. Vet. Surg. 21(6):475-479.

Salata L.A., Hatton P.V., Devlin A.J., Craig G.T. \& Brook I.M. 2001. In vitro and in vivo evaluation of e-PTFE and alkali-cellulose membranes for guided bone regeneration. Clin. Oral Implants 12(1):62-68.

Schuman L., Buma P., Versleyen D., de Man B., van der Kraan P.M. \& van den Berg W.B. 1995. Chondrocyte behavior within different types of collagen gels in vitro. Biomaterials 16:809-814.

Simon T.M. \& Jackson D.W. 2006. Articular cartilage: injury pathways and treatment option. Sports Med. Arthrosc. Rev. 14(3):146-154.

Warrer K. \& Karring T. 1992. Guided tissue regeneration combined with osseous graft in suprabony periodontal lesions. J. Clin. Periodont. 19(6):373-380.

Zar J.H. 1999. Biostatistical Analysis. 4th ed. Prentice Hall, New Jersey. $663 p$. 